\title{
Portraying Students' Perception of Teacher's Roles in EFL Classroom through Drawings Analysis: Social Semiotic Approach
}

\author{
Fitria Kamelia, Wahyu Budi Riyanda \\ Universitas Pendidikan Indonesia, Bandung, Indonesia \\ fitriakamelia@ymail.com \\ riyandaa@gmail.com
}

\begin{abstract}
It is pivotal to know whether or not teachers have thoroughly accomplished their roles in order to build an effective teaching in the classroom. Hence, the researcher aimed to investigate the realization of teacher's roles in the classroom through students' perception. The participants were the 11th grade students in a state senior high school in Banjarmasin. They expressed their perception on teacher's roles through drawings. The drawings were analyzed based on social semiotic approach to seek only the compositional meaning. The compositional meaning is analyzed through 4 components: information value, framing, salience, and modality. However, information value became the only concern of this study. The Information Value is realized through the placement of picture's element analysis, whether it is top-bottom, left-right, or central. Among 25 drawings, the vast majority was found in the top-bottom placement. On the basis of findings, 5 expected teacher's roles were almost fully realized. What this study has done differently to previous ELT studies is in using students' drawing as the data to investigate students' perception. Future researchers are suggested to implement further drawing-based studies in different contexts.
\end{abstract}

Keywords: teacher's role, perception, drawing analysis

\section{INTRODUCTION}

These days, teachers, and researchers in academic domain are facing the issue of how to develop and maintain the quality of education. Teachers are an important actor in education in which the quality of education partially depends on them. According to Harrison and Killion (2007), teachers assume a wide range of roles to support school and students' success. Whether these roles are assigned formally or shared informally, they build the entire school's capacity to improve. Because teachers can lead in a variety of ways, many teachers can serve as leaders among their peers.

Furthermore, it is pivotal to know what roles that students receive in the learning process, and to know whether or not teachers have thoroughly accomplished their roles. Hence, the researcher aims to investigate the realization of those teachers' roles in the classroom through the information of students' perception using their drawings. Analyzing drawing as one kind of multimodal analysis belongs to semiotic analysis. Turkcan (2013) proposes that semiotic approach has increasingly gained importances so that people, who live in a visual bombardment today, can analyze the codes included in visual culture and understand the form of visual communication. The semiotic approach utilized in this study is social semiotic approach. Then, what is developed by Kress and van Leeuwen's (1996) and Van Leeuwen and Jewitt (2001) is how we can use social semiotics as an analytical tool to access these meanings by drawing on the contexts and cultures of its production and how we as individuals assign meanings to our texts through our prior knowledge, exposure and use of semiotic resources and modal affordance in our communicative practices.

Thus, this research is aimed to portray students' perceptions on their teacher's roles in EFL classroom by using social semiotic approach. The participants are the $11^{\text {th }}$ grade students in a state senior high school in Banjarmasin. The students express their perceptions on teachers' role through drawings. Clarebout et al (2007) argues that drawings can be used to identify nuances and ambivalences within a person's belief system, indicating they would be useful when studying pupil conceptions. This research strategy is increasingly being used to probe students' feelings about how they teachers accomplish their role in the classroom. This research is going to answer a single research question: How do students perceive their teacher's roles in the EFL classroom viewed from their drawings?

\section{LITERATURE REVIEW 2.1 TEACHERS' ROLES}

To achieve an effective teaching-learning process, teachers ought to know their roles in the classroom. In the process of transferring knowledge, teachers are expected to play particular roles. However, the implementation of the role itself depends on the situation of the educational institution, the students, and the subject matter we are required to teach, and so on. Considering those various situations, teachers are required to play more than one role. According to Harmer (2007), there are five roles of the teachers: (1) teacher as a controller, (2) Teacher as a prompter, (3) teacher as participant, (4) teacher as resource, and (5) teacher as tutor. Furthermore, those five roles are becoming the primary issue in this research. The writer intends to investigate the realization of those five roles by analyzing students' perception through their drawings 


\subsection{SOCIAL SEMIOTIC APPROACH}

In this study, the semiotic sign which will be analyzed is students' drawing. Images show not the thing actually seen but its representations in human consciousness. Turkcan (2013) proposes that semiotic approach has increasingly gained importance so that people, who live in a visual bombardment today, can analyze the codes included in visual culture and understand the form of visual communication.

Halliday (1978) states that social semiotic theory provides the basis for the study of semiotic resources other than language (e.g. images, architecture, music, mathematical symbolism, gesture, clothing). Moreover, Aiello (2006) argues that the main aim of social semiotics is to look systematically at how textual strategies are deployed to make certain meanings. He also adds that social semiotics concentrates on practices of meaning-making and considers how we make meaning using various semiotic resources, modes and their affordances. Then, what is developed by Kress and van Leeuwen's (1996) and Van Leeuwen and Jewitt (2001) is how we can use social semiotics as an analytical tool to access these meanings by drawing on the contexts and cultures of its production and how we as individuals assign meanings to our texts through our prior knowledge, exposure and use of semiotic resources and modal affordance in our communicative practices. Kress and Van Leeuwen (1996) have extended this idea to images, using a slightly different terminology: representational meaning, interactive meaning, and compositional meaning.

In the context of this research, the most relevant branch of the meaning analysis is 'compositional meaning'. Compositional meaning brings together the individual bits of representation and interaction into the kind of wholes we recognize as specific kinds of text or communicative event (Halliday, 1978). According to Jewitt (2009), the compositional meaning is analyzed through 4 components: information value, framing, salience, and modality.

\subsection{RELATED STUDIES}

There are various studies related to teachers' role conducted by the previous researchers. Xiongyong, Samuel, and Hua (2012) investigated EFL teachers' roles in the classroom, based on the findings, most EFL teachers in China's secondary schools are unable to mediate students' learning due to the misconception of mediation and the fact that most EFL learners sit passively in class receiving knowledge from the teacher rather than communicating effectively in the language. Besides, Koutrouba, Baxevanou, and Koutroumpas (2012) found that according to students, teachers exert didactic power mainly by exhibiting profound knowledge and applying effective teaching and assessment methods, while they exert legitimate power through implementing rules, inflicting punishment and controlling students' behaviour. Studies in the field of teacher's roles are commonly conducted by utilizing a set of questionnaire, observation, or interview. There are no studies involving multimodal data such as students' drawing like the present research is doing.

\section{METHODS}

\subsection{RESEARCH DESIGN}

In line with the goals of this study, this study focuses on portraying students' perception on teachers' role in the EFL classroom. This study uses descriptive method and qualitative approach. The descriptive method is used to describe students' perception. Flick (2007) states that qualitative research is 'an extension of the tools and potentials of social research for understanding the world and producing knowledge about it. Hence, it can provide rich insight into individuals and groups, and, how people interpret their experiences, how they construct their worlds, and what meaning they attribute to their experiences (Merriam, 2009). Since the objective of this research is to investigate students' perception, the qualitative approach is considered suitable to support the entire research process.

\subsection{SAMPLE}

25 students of a public senior high school in Banjarmasin are involved in this study. All of the participants are in the eleventh grade.

\subsection{DATA ANALYSIS}

The data are in the form of drawings. The researcher interprets all drawings to reach the aim of this study which is to portray students' perception on teachers' role in the EFL classroom. Moreover, the data will be analyzed based on social semiotic approach. The social semiotic approach itself is narrowed to seek only the compositional meaning of the drawings to get the expected goal of this study. The compositional meaning is analyzed through 4 components: information value, framing, salience, and modality. These four components will become guidance for the researcher to execute the data. The drawings then are classified into 5 category of teacher's roles in the classroom proposed by Harmer (2007): (1) Controller, (2) Prompter, (3) Participant, (4) Resource, and (5) Tutor. Afterwards, the findings were further discussed comprehensively. Lastly, the researcher drew some conclusions, and gave suggestion.

\section{FINDINGS}

The purpose of this study was to obtain a diversity of information transmitted through drawings. Based on the data obtained, the students were able to describe their perception of their teacher's role based on their experience through drawings creatively.

The drawings were analyzed based on social semiotic approach. The social semiotic approach itself is narrowed to seek only the compositional meaning of the drawings to get the expected goal of this study. The compositional meaning is analyzed through 4 components: information value, framing, salience, and modality. However, among the 4 components, Information Value became the only concern of this study. The Information Value is realized through analyzing the placement of picture's element, whether it is top-bottom, left-right, or 
central. After analyzing the compositional meaning or the information value by analyzing the placement of picture elements, students' perception of their teacher's role was gained.

Among 25 drawings collected, the vast majority was found in the top-bottom placement. All that meant 14 of them gave idealized, or generalized essence of information of their teacher's role. Besides, they also provided down-to-earth information (specific information, real information such as documentary evidence) related to their teacher's role.

Table 1: Compositional Meaning: Information Value Placement
of Pictures
Elements

Left-Right 4 - The students give something the Freq Interpretation viewer already knows, familiar and agreed departure point for the message about teacher's role.

- The students provide commonsensical, self-evident information related to their teacher's role.

- The students give something not yet known and not yet already agreed upon by the viewer, something to which the viewer must pay special attention related to their teacher's role.
Table 1, Cont.

\begin{tabular}{lll}
\hline & $\begin{array}{l}\text { - } \\
\end{array}$ & $\begin{array}{l}\text { The students provide } \\
\text { problematic, contestable, the } \\
\text { information about teacher's } \\
\text { role. }\end{array}$ \\
\hline Top-Bottom 14 & $\begin{array}{l}\text { - } \\
\text { The students give idealized, or } \\
\text { generalized essence of } \\
\text { information of their teacher's } \\
\text { role. } \\
\text { - }\end{array}$ \\
& $\begin{array}{l}\text { The students provide down-to- } \\
\text { earth information (specific } \\
\text { information, real information } \\
\text { such as documentary evidence) } \\
\text { related to their teacher's role. }\end{array}$ \\
\hline Centre & $\begin{array}{l}\text { The students describe 'what } \\
\text { teacher's role is', merge each } \\
\text { element's meaning to one sense. }\end{array}$ \\
\hline Total & $\mathbf{2 5}$ & \\
\hline
\end{tabular}

Subsequently, the visual analysis which focuses on the analysis of placement of the picture's element has successfully generated some derived interpretation of students' perception of their teacher's role. The table below describes general perception of students regarding the teacher' roles that have been implemented in their classroom.

Table 2: Students' Perception of Teacher's Role

\begin{tabular}{llllll}
\hline Response & \multicolumn{3}{l}{ Students Perception } & & \\
& \multicolumn{3}{l}{ Teacher as a } \\
& controller & $\begin{array}{l}\text { Teacher as a } \\
\text { prompter }\end{array}$ & $\begin{array}{l}\text { Teacher as a } \\
\text { participant }\end{array}$ & $\begin{array}{l}\text { Teacher as a } \\
\text { resource }\end{array}$ & $\begin{array}{l}\text { Teacher as a } \\
\text { source of } \\
\text { motivation }\end{array}$ \\
\hline Positive & 4 & 1 & 2 & 5 & 9 \\
\hline Negative & 2 & & & & \\
\hline
\end{tabular}

The data coding above is based on teacher's role classification by Harmer (2007): (1) teacher as a controller, (2) teacher as a prompter, (3) teacher as participant, (4) teacher as resource, and (5) teacher as tutor. Based on the data obtained, the teacher has completed those 5 roles.

\subsection{Teacher as a controller}

It was assumed that 4 students thought that their teacher acts as a controller. It was revealed that these 2 students believed that their teacher is a very wise and kind person who is able to manage all activities in the classroom, and to control all students' behavior. The classroom management done by the teacher is mostly realized by enjoyable teaching methods. They also stated that their teacher often gives them information which brings them to a brighter perspective. However, it was found that there was 2 students who conveyed a negative response regarding teacher as a controller. It was seen from their drawing that when a teacher becomes a controller, he or she will be dominating the class. Considerably, the domination can make the class boring and contain monotonous activities. These 2 students presumed that when teacher acts as a controller, it will shape a restriction in terms of students' choice.

\subsection{Teacher as a prompter}

Based on the data obtained, there was a student who perceived her/his teacher as a prompter. It was revealed from the drawing that the teacher always tells her/him what to do when 
she/he lose the thread of what is going on. The teacher helps her/him to proceed things. No negative response found toward this role.

\subsection{Teacher as a participant}

There were 2 drawings indicating the role of teacher as a participant. All of them indicated positive response. There are some moments when teacher might want to join in an activity not merely as a teacher, but also as a participant in his/her own right. It was revealed from these drawings that students experienced some moments where their teacher involved in students' activities, and they considered it was very helpful. At the same time they felt that their teacher's participation created a warmhearted relationship that eventually made a good rapport between students and teacher.

\subsection{Teacher as a resource}

It was revealed that 5 drawings indicating the existence of teacher as a resource. It was such a big number among all. For the most part, the students experienced numerous moments where the teacher willingly became a powerful source in their learning process. They considered it very helpful for their academic improvement. In their opinion, a teacher is such a light in the darkness that can assist them in each condition they face. They also expected that a teacher should have plentiful knowledge so that they could get a knowledgetransmission from the teacher.

\subsection{Teacher as a tutor}

Unfortunately, based on the data obtained, there were no students who perceived their teacher as a tutor. Actually, the role as a tutor is very important. A teacher should sometimes works with one student as a person charged with an instruction and guidance of another. This role will be exceedingly beneficial for students' academic improvement.

\subsection{Teacher as a motivator}

Among 25 data collected, there were 9 of them which could not be classified to 5 roles proposed by Harmer (2007). At the first, these 9 drawings seemed unidentifiable, yet there was a pattern found. These drawings, all of them, referred to the same point. Nine students believe that their teacher acts as a motivator. Moreover, it was observed that the students felt mentally encouraged by teacher's motivation in the classroom. The motivation derived from their conception was in the form of teacher's support, reinforcement, and verbal motivation. Some of them admitted that teacher's motivation encouraged them a lot. In other words, it becomes an extrinsic motivation that triggers their intrinsic motivation.

\section{CONCLUSION AND SUGGESTION}

This study has discussed perception of teacher's role from a small group of high school students and has resulted in some different dimensions of students' responses. Even though this study was conducted to a small group, the researcher believed that documenting students' perception in particular could create a powerful contribution to the knowledge base and inspiration for future research efforts. This study has also explored the prospect of drawings as a tool of eliciting students' insight. Drawing becomes nonverbal communication which enables students to show up their ideas and emotions without any restriction. Moreover, drawing could be helpful for students to conceptualize their reality or experience. However, students need to be encouraged to draw so that they could feel that their drawing is respected. Therefore, education should begin with students' surroundings and their thoughts. In a word, if students' perception of teacher's role is taken into account, a significant improvement of teaching context will be earned. Teachers and educational institution are expected to be more aware of the emotional, social, and intellectual impacts which might happen to students after the teaching process. Future researchers are suggested to conduct wider studies regarding to students' perception on teacher's role in order to make teaching and learning process becomes more profitable. This study has a number of limitations which need to be addressed in future research. The future research is recommended to investigate teacher's role in a broader context, in other school types like vocational high school, elementary school, or even university.

\section{REFERENCES}

Aiello, G. (2006). Theoretical advances in critical visual analysis: perception, ideology, mythologies, and social semiotics. Journal of Visual Literacy, 26 (2), 89-102.

Clarebout, G., Depaepe, F., Elen, J., \& Briell, J. (2007). The use of drawings to assess students' epistemological beliefs. Paper presented at the Biannual Conference of the European Association for Research on Learning and Instruction, Budapest, Hungary, August.

Flick, U. (2007). Designing qualitative research. Thousand Oaks: CA.

Halliday, M. (1978). Language as social semiotic. Edward Arnold: London.

Harrison, C. \& Killion, J. (2007). Ten roles for teachers leaders. Teachers as Leaders, 65 (1), 74-77.

Harmer, J. (2007). The practice of english language teaching. England, UK: Pearson Education Limited.

Jewitt, C. (2009). The routledge handbook of multimodal analysis. London:Routledge.

Koutrouba,K., Baxevanou,E., \& Koutoumpas,A. (2012). High school students' perceptions of and attitude towards teacher power in the classroom. International Education Studies, 5(5), 185-198.

Kress, G. (2009). Multimodality: a social semiotic approach to contemporary communication. London: Routledge.

Kress, G. \& van Leeuwen, T. (1996). Reading images: the grammar of visual design. Routledge, London.

Merriam, S. (2009). Qualitative research: a guide to design and implementation. Jossey-Bass: San Francisco, CA.

Van Leeuwen, T. \& Jewitt, C. (2001). Handbook of visual analysis. Sage: London. 
Xiongyong, C., Samuel, M., \& Hua,C.(2012). Evaluation on EFL teacher roles from the perspective of mediation. International Review of Social Sciences and Humanities, 3(1), 117-134.

Turkcan, B. (2013). Semiotic approach to the analysis of children's drawings. Educational Sciences: Theory \& Practice, 13 (1), 600-607. 